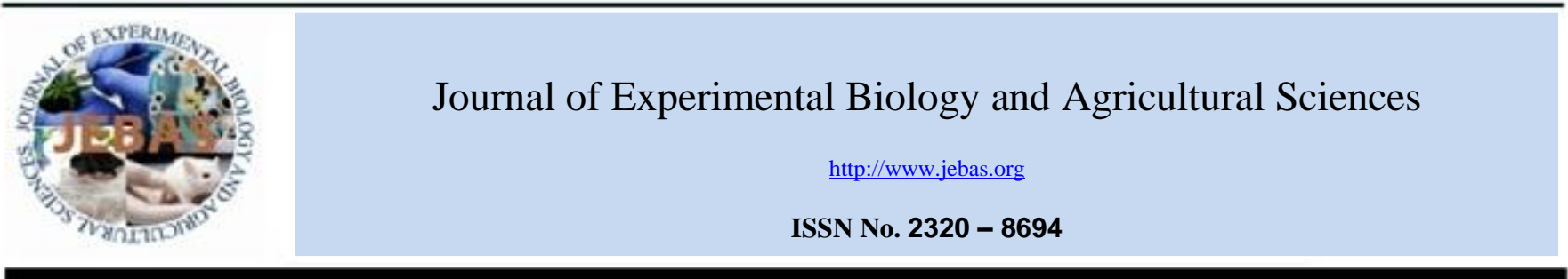

\title{
A WEB-BASED CROSS-SECTIONAL STUDY AMONG INDIANS REVEALS A WILLINGNESS SHIFT REGARDING COVID-19 VACCINE UPTAKE AFTER THE SECOND WAVE
}

\author{
Sakshi Kamboj ${ }^{1, \#}$, Siya Srivastava ${ }^{2, \#}$, Sana Siddiqui $^{3}$, Rohit Singh $^{4 *}$ \\ ${ }^{1}$ Sophisticated Analytical Instrument Facility, CSIR-Central Drug Research Institute, Lucknow- 226031, India \\ ${ }^{2}$ Department of Computer science and engineering, Babu Banarasi Das National institute of technology \& management (BBDNITM), Lucknow- 226028, India \\ ${ }^{3}$ Department of Bioscience and Biotechnology, Banasthali Vidyapith, Jaipur, Rajasthan-304022, India \\ ${ }^{4}$ Department of Pharmaceutical Chemistry, College of Pharmacy, JSS Academy of Technical Education, C-1/A, Sector-62, Noida, Uttar Pradesh-201309, India \\ \#contributed equally
}

Received - July 11, 2021; Revision - September 21, 2021; Accepted - October 04, 2021

Available Online - October 30, 2021

DOI: http://dx.doi.org/10.18006/2021.9(5).647.656

\section{KEYWORDS}

Vaccine hesitancy

COVID-19

Second wave

Willingness shift

Web-based online survey

\begin{abstract}
This study aimed to determine the shift in willingness regarding the COVID-19 vaccine after the second wave. The study attempts to understand the willingness towards COVID-19 vaccination by assessing the public's knowledge, concerns, and attitude regarding the vaccine. Between May 16 to May 28, 2021, the individuals of the general population were invited to fill the online questionnaire. Total 711 participants had given their informed consent and completed the questionnaire on their background and vaccination behavior-related variables such as knowledge, practices, and their concerns regarding the vaccine. Before the launching of the vaccine, people were less likely to get vaccinated (63.6\%); however, once the second wave hit India, attitudes towards vaccines shifted dramatically, and the figure increased to $84.4 \%$. A significant proportion of the population is now willing to take the vaccine. There are several socio-demographic differences regarding knowledge and concerns related to vaccines, especially in age and gender groups. The success of a COVID-19 vaccination program is determined not just by the vaccine's efficacy, but also by its uptake. To ensure optimum vaccination uptake, there is an immediate need for the most effective policy and communication.
\end{abstract}

* Corresponding author

E-mail: rohit.singh@jssaten.ac.in (Dr. Rohit Singh)

Peer review under responsibility of Journal of Experimental Biology and Agricultural Sciences.

Production and Hosting by Horizon Publisher India [HPI] (http://www.horizonpublisherindia.in/).

All rights reserved.
All the articles published by Journal of Experimental Biology and Agricultural Sciences are licensed under a Creative Commons Attribution-NonCommercial 4.0 International License Based on a work at www.jebas.org.

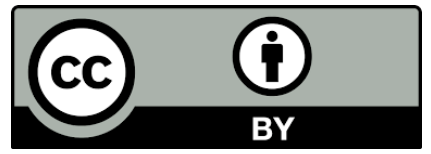




\section{Introduction}

WHO declared COVID-19 as a global pandemic on March 11, 2020 (World health organization, archived: WHO timelineCOVID-19, 2021) and India reported its first case of COVID-19 in Kerala on January 27, 2020 (Ministry of home affairs, India, https://www.mygov.in/covid-19 accessed on 02.06.2021). Since then, India has been hit by the two waves of COVID-19 and the second surge has been more devastating than the first one. Till the date of manuscript writing of this survey report, the total tally of COVID-19 infected people reached 2,98,27,268 and total causality 3,85,220 (Ministry of home affairs, India, https://www.mygov.in/covid-19 accessed on 02.06.2021). Grappled with the second wave, medical professionals predicted that the third wave will arrive sooner (India could see a third wave in 6-8 weeks if Covid-appropriate behavior is not followed: AIIMS chief Randeep Guleria, 2021). Since there was no effective therapy available at the time, the government urged individuals to take precautions such as hand washing, wearing a facemask, and social distancing however, the latter has taken its toll on the mental health and social well-being of the people (Sulprizio et al., 2021).

These preventive measures were having minimal success in limiting the spread of the deadly COVID-19 disease, and vaccination was the only ray of hope for the population. The fact that vaccination is the only weapon to fight against this pandemic and avoid the accompanying problems has been highlighted in earlier research (Sallam, 2021). There have been 13 distinct vaccinations provided worldwide (across four platforms), with India having three primary vaccines, namely Covaxin, Covisheild, and Sputnik V, which have shown encouraging effects against coronavirus infection (World health organization, Coronavirus disease: Vaccine, 2021). With such a large population, the mammoth task of vaccinating the entire country is another challenge for the Indian government and relevant agencies. However, after the approval of COVID19 vaccines, the government was trying to vaccinate the people based on risk priority. To maintain continued success, it is necessary to maintain a high level of vaccine coverage. Still, the biggest hurdle before the vaccination drive was the hesitancy of people reported in earlier studies (Dubé et al., 2013).

According to the SAGE working group, vaccine hesitancy signifies the delay in acceptance and refusal of vaccine despite its availability (MacDonald et al., 2015). It was also included in the list of threats to global health in 2019 (Vaccine Hesitancy, 2015). This Vaccination hesitancy poses a significant barrier to achieving herd immunity against the COVID-19 pandemic. To overcome this issue, it is critical to have a positive attitude toward the vaccine, as well as knowledge and perceptions about it. The causality in the second wave, as well as the anticipated threat of the third wave, terrified the general public, causing them to change their minds about getting the COVID-19 vaccine.

In India, there have been few studies on public readiness or apprehension to get vaccinated. The goal of this study was to learn more about India's perceptions after the devastating second wave of COVID-19 hit the country. To begin, we assessed participants' knowledge, attitudes, and practices toward the COVID-19 vaccine. Finally, we looked at how perceptions about the COVID-19 vaccine changed over time, as well as how people thought about COVID-19 vaccination uptake.

\section{Materials and Methods}

A validated questionnaire with some adjustments was used in the web-based cross-sectional survey of the general populace (Kumari et al., 2021a) The internal consistency of the questionnaire was tested using Cronbach's alpha in Excel, and the result was 0.74, which is acceptable. The sample size was calculated using EpiInfo $^{\mathrm{TM}}$ 7.2.4.0 software from the Centers for Disease Control and Prevention (CDC), Atlanta, Georgia, USA. The minimal sample size required to represent the adult Indian population as per the 2011 census (Office of the Registrar General \& Census Commissioner, India, 2021) with a $95 \%$ confidence interval and an acceptable margin of error of $3.7 \%$, given $50 \%$ predicted frequency, was found to be 702. All the statistical analysis (Descriptive statistics and Chi-square test) was performed in SPSS 16 (IBM statistics).

This broad web-based cross-sectional survey was conducted via an online platform between May 16, 2021, and May 28, 2021. The questionnaire was anonymous. The Google form questionnaire was sent using a snowball sampling approach. Investigators sent the Google form link by email, Whatsapp chat, Instagram, and Facebook to their personal and social acquaintances. The questionnaire was written in both English and the respondent's native language, keeping in mind that the respondents came from a variety of educational backgrounds. Respondents were told about the study aims, declaration of confidentiality, and voluntary participation before beginning to fill out the questionnaire. In cases when respondents lacked technological skills, investigators conducted the telephone interview on their behalf and recorded their responses in the Google form. Respondents above the age of 18 belonging to different socio-demographic backgrounds such as age, gender, marital status, chronic disease history, socioeconomic status, and residence were included in the study to fulfill maximum diversity. 


\section{Results}

\subsection{Participant's characteristics}

In total, 711 participants from 26 different states aged 18 and above took part in the survey. Among these, 312 (43.9\%) females and $399(56.1 \%)$ males with different educational backgrounds participated in this survey with the majority having an undergraduate or postgraduate degree. The urban population accounts for $77.7 \%$ of the total number. Only 31 people $(4.4 \%)$ said they had a history of chronic disease, while the remainder said they were healthy. There were 166 (23.3\%) participants who had already had the vaccine, but there were still a considerable number of people who had not received the vaccine. The healthcare system was represented by $15.6 \%$ of the participants and more than half of participants were unmarried (Figure 1).

\section{GENDER}

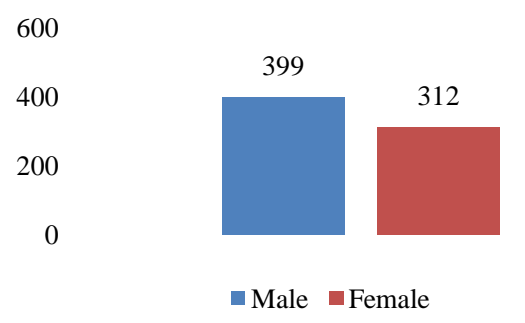

\section{HEALTHCARE WORKER}

800
600
400
200
0

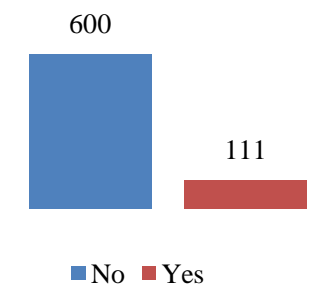

\section{EDUCATION}

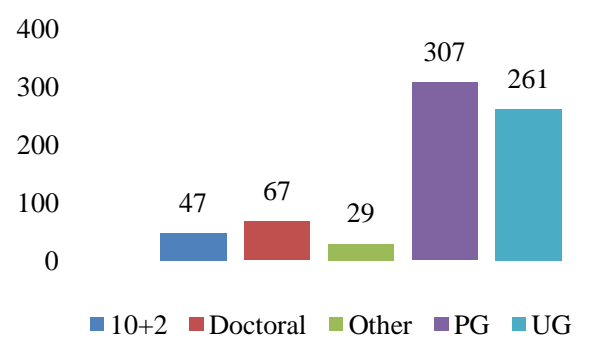

COVID-19 VACCINE UPTAKE

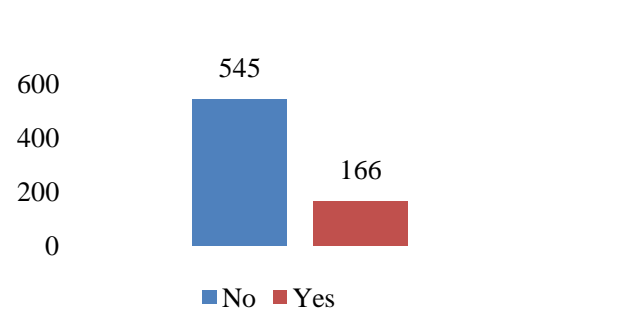

AGE

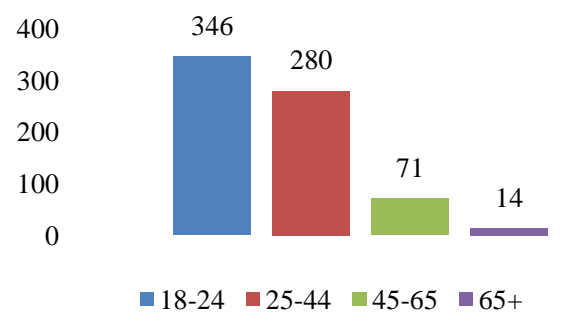

\section{CHRONIC ILLNESS}

800
600
400
200
0

670

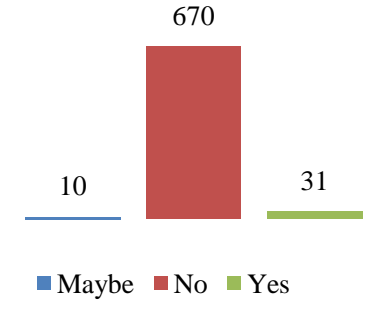

MARITAL STATUS

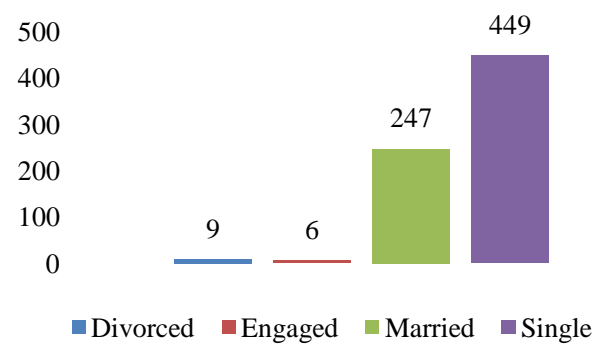

\section{LIVING PLACE}

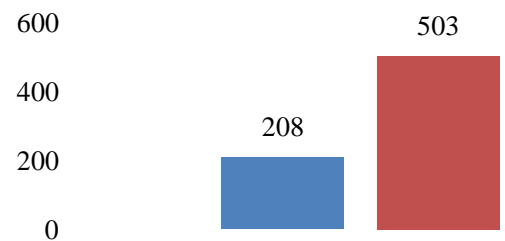

Figure 1 Socio-demographic profile of participants

Journal of Experimental Biology and Agricultural Sciences http://www.jebas.org 
Persons recovered from COVID-19 infection

Persons having active COVID-19 infection

Patients with chronic diseases like diabetes, hypertension and heart diseases

Pregnant ladies and lactating mother

Adults $>=18$ years

Children and adolescents $<18$ years of age

Infants $<1$ of age

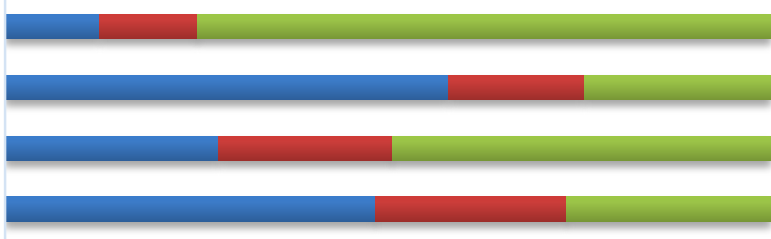

要
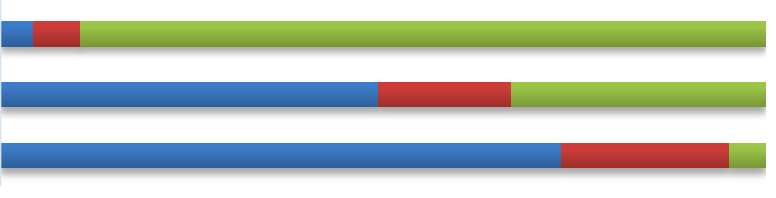

Not eligible Don't know Eligible

$0 \%$

$20 \%$

$40 \%$

$60 \%$

$80 \%$

$100 \%$

Figure 2 The responses of participants regarding the knowledge associated with COVID-19 vaccination.

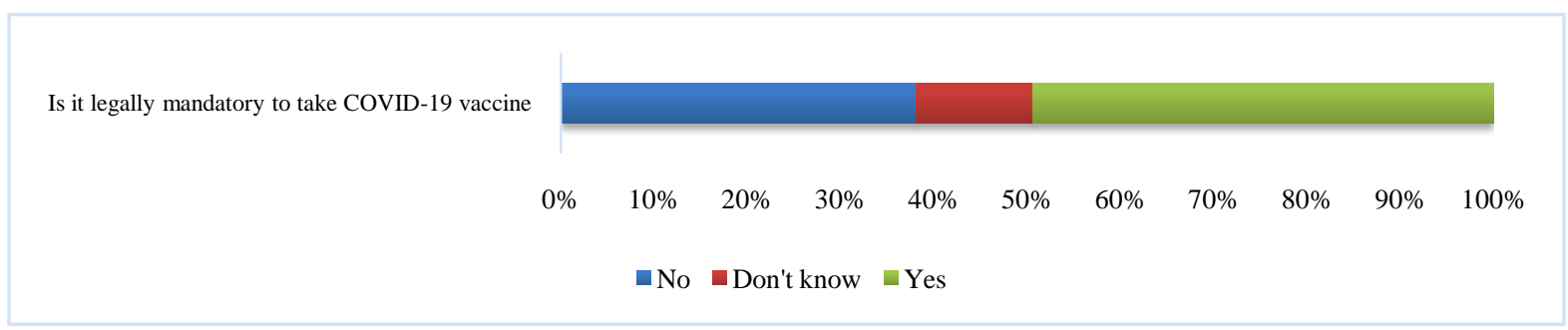

Figure 3 The response of participants regarding the knowledge associated with COVID-19 vaccination.

\subsection{Knowledge regarding COVID-19 vaccine}

The knowledge regarding the COVID-19 vaccine is quite varied, with the majority of people correctly identifying who should be vaccinated, such as adults $(89.4 \%)$ and people who have recovered from COVID-19 (74.8\%), and who should not be vaccinated, such as infants or children under the age of 18 (49.4\%).

However, there is still a lack of information about inoculation for pregnant women and breastfeeding mothers, since the majority of people either don't know (24.9\%) or give incorrect answers (26.7\%). A similar tendency has been observed in the immunization of children under the age of 18, individuals with chronic illnesses, and people who are infected with COVID-19. The immunization of infants, children, pregnant women and lactating mothers, chronic disease patients, and those with active COVID-19 infection has a significant correlation with where they live $(\mathrm{p}<0.05)$. People belonging to the urban area were having more knowledge regarding vaccination (Figure 2). The knowledge of pregnant women and breastfeeding mothers about vaccination has been linked to gender $(\mathrm{p}<0.01)$.

Individuals are perplexed by vaccination's legal requirement, as just $38.11 \%$ of people are aware that it is not legally obligated. This is strongly associated with age, location of residence, and education $(\mathrm{p}<0.05)$, as persons in urban regions with higher age groups and education, have better information than people in rural areas or with lower education (Figure 3).

\subsection{Source of information influencing vaccination}

During the pandemic, news organizations and social media platforms are the key sources of information about COVID-19 and its prophylaxis. However, it also promotes some falsehoods, making individuals skeptical of the information. Various sources of information, such as news networks (80.9\%), government organizations $(76.2 \%)$, social media platforms (73.3\%), discussions among friends and family (85.2\%), and healthcare providers $(80.7 \%)$, have influenced people's decision-making regarding vaccination (Figure 4). The information gained from reputable sources such as government agencies is substantially associated with education $(\mathrm{p}<0.05)$, as persons with a higher level of education are more likely to believe in a more trustworthy source of information. Because people living in urban regions have more access to diverse social media platforms than people living in rural areas, the influence of non-reliable sources such as social media platforms is strongly associated with residency $(\mathrm{p}<0.05)$.

Furthermore, additional reputable sources, such as healthcare providers, have shown a significant relationship with age $(\mathrm{p}<0.05)$. It has been observed that healthcare practitioners have a strong effect on the younger age group (18-24), making it the major obligation of healthcare providers to deliver accurate vaccination information to their patients. 
Healthcare provider

Discussion amongst friends and family

Social media (facebook, instagram and whatsapp)

Government agencies

News from National TV/Radio

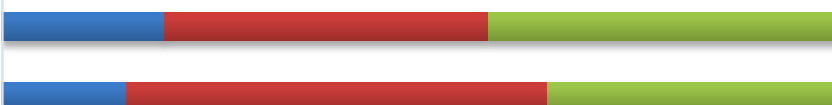

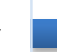

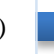

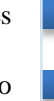

\begin{tabular}{|c|c|c|c|c|c|}
\hline & $0 \%$ & $20 \%$ & $40 \%$ & $80 \%$ & $100 \%$ \\
\hline Insignificant effect & So & nificant effect & Very significant & & \\
\hline
\end{tabular}

Figure 4 The response of participants regarding the source of information that affect their opinion associated with COVID-19 vaccination.

Currently when second wave worstly hit Indian population (April - till date) do you want to take the vaccine

When Vaccine was launched and available for uptake (period from Jan'2021 to April'2021

Period from Sep'2020 to Jan'2021, when covid cases had reduced significantly

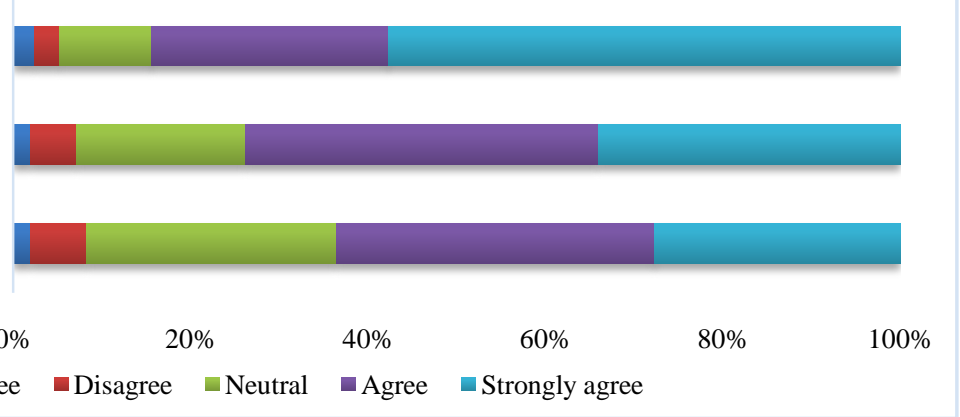

- Strongly disagree $\quad$ Disagree $\quad$ Neutral $\quad$ Agree $\quad$ Strongly agree

Figure 5 The responses of willingness about COVID-19 vaccine uptake during different period.

I will recommend my family and friends to get vaccinated against COVID-19

I am willing to get the COVID-19 vaccine, even if 1 have to pay to get it.

I will prefer to acquire immunity against COVID-19 naturally (Ayurvedic treatment / homeopathic) rather than by vaccination.

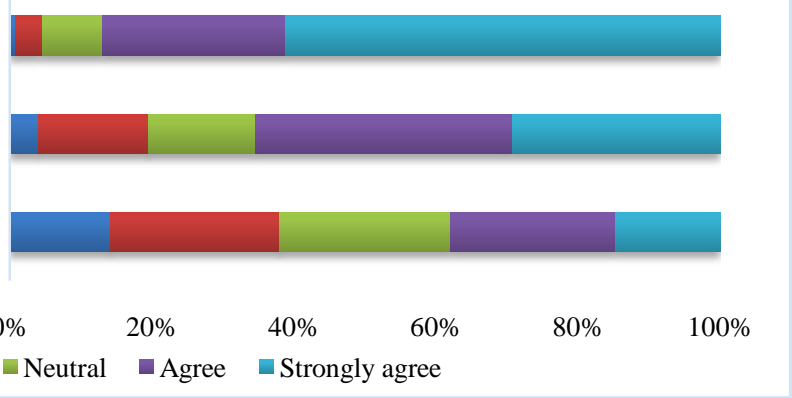

\begin{tabular}{|c|c|c|c|c|c|c|}
\hline & & $0 \%$ & $20 \%$ & $40 \%$ & $80 \%$ & $100 \%$ \\
\hline Strongly disagree & Disagree & Neutral & - Agree & Strongly agree & & \\
\hline
\end{tabular}

Figure 6 The responses of questions related to different aspect about COVID-19 vaccine.

\subsection{Opinions regarding COVID-19 vaccine}

From September 2020 to January 2021, Pre-launch of the vaccine, the vaccination was met with a lot of skepticism; just $63.6 \%$ of people were willing to take it. The willingness during this period is significantly associated with marital status $(\mathrm{p}<0.05)$. From January 2021 to April 2021, there was a considerable increase in the number of people wanting to get the vaccine $(73.8 \%)$. When the second wave of COVID-19 hits India, people's perceptions were radically altered, and $84.4 \%$ of the population agreed to take the vaccine (Figure 5).
There is an overall positive attitude towards the vaccination; people were willing to take vaccination even if they had to pay (65.4\%) and were ready to recommend it to their family and friend (86.9\%) (Figure 6). The willingness to pay for the vaccine is significantly associated with age $(p<0.05)$, gender $(p<0.01)$, living $(\mathrm{p}<0.01)$, and marital status $(\mathrm{p}<0.01)$. However, when it came to naturally acquired immunity, only $38 \%$ of people strongly disagreed with the statement, while the rest of the population was quite perplexed; this factor is significantly associated with age $(\mathrm{p}<0.01)$, living $(\mathrm{p}<0.01)$, education $(\mathrm{p}<0.01)$, marital status $(\mathrm{p}<0.01)$, and socioeconomic status $(\mathrm{p}<0.05)$. 
I think it will help me eradicating COVID-19 infection

Many people are taking the COVID-19 vaccine

There is sufficient data regarding the vaccine 's safety and efficacy released by the government

I believe that taking the COVID- 19 vaccine is a societal responsibility

I feel the benefits of taking the COVID-19 vaccine outweighs the risks involved

My healthcare professional/ doctor has recommended me

COVID-19 vaccine is available free of cost

I believe COVID-19 vaccine will be useful in protecting me from the COVID- 19 infection

I think there is no harm in taking COVID-19 vaccine.
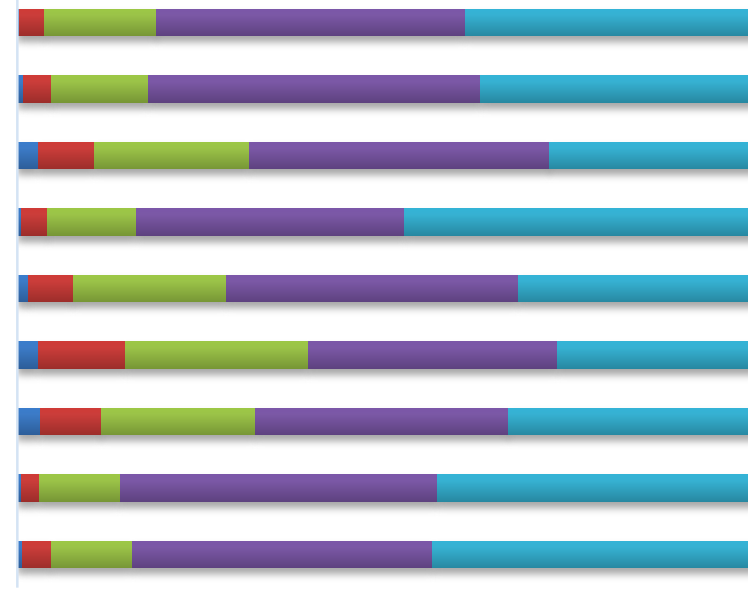

$\begin{array}{lllllllll} & 0 \% & 20 \% & 40 \% & 60 \% & 80 \% & 100 \%\end{array}$

- Strongly disagree $\quad$ Disagree $\quad$ Neutral $\square$ Agree $\quad$ Strongly agree

Figure 7 The responses of factors related to decision making about COVID-19 vaccine.

COVID - 19 vaccine is being promoted for commercial gains of pharmaceutical companies

I might have some unforeseen future effects of the COVID-19 vaccine

COVID-19 vaccine was rapidly developed and approved

COVID- 19 vaccine may be faulty or fake

I might have immediate serious side effects after taking COVID-19 vaccine

COVID-19 vaccine might not be easily available to me
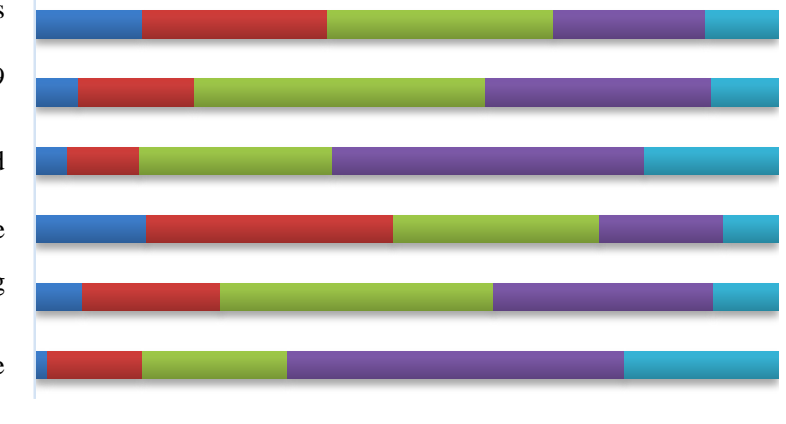

- Strongly disagree $\quad$ Disagree $\quad$ Neutral $\square$ Agree $\square$ Strongly agree

Figure 8 The responses of participants regarding the Concerns associated with COVID-19 vaccination.

\subsection{Factors responsible for the decision making of vaccination}

Several factors affected the COVID-19 vaccine acceptance among people, such as people believed that there is no harm in taking the vaccine $(84.3 \%)$, vaccination will help in protecting them from infection $(86.1 \%)$, there is sufficient data available on the COVID-19 vaccine $(68.6 \%)$, the vaccine will aid in the eradication of COVID19 infection $(81.2 \%)$. Various motivating factors such as no harm in taking vaccine $(\mathrm{p}<0.05)$, recommendation by the health care professionals $(p<0.05)$, its availability for free of cost $(p<0.05)$ are significantly associated with age, as the higher the age of the people, the greater the motivation to get vaccinated (Figure 7).

Motivating factors such as the benefits of the vaccine outweigh the risk $(71.1 \%)$ and people considering it as a societal responsibility $(83.8 \%)$ are significantly associated with age $(\mathrm{p}<0.05)$, and living place $(\mathrm{p}<0.05)$ as better the place of residence, better knowledge regarding the vaccine. People considering it as a societal responsibility is also significantly associated with education $(\mathrm{p}<0.01)$ as a more educated person will have a better knowledge regarding vaccines (Figure 8).

\subsection{Concerns regarding COVID-19 vaccination}

Results of the current survey suggested that the participants seemed to have a wide spectrum of opinions. There are several concerns regarding the availability of vaccine (66\%), rapid development and approval of vaccine (59.9\%), major adverse effects following vaccination (38.2\%), undiscovered future vaccine effects (39.4\%). The majority of the respondents showed their faith in the COVID-19 vaccine (75.4\%), ruling out the possibility that it is flawed or fake. 
After getting COVID-19 vaccine, I don't need to follow preventive measures such as wearing a mask, sanitization and social distancing

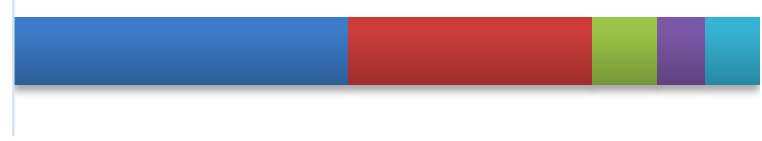

$$
\begin{array}{llllll}
0 \% & 20 \% & 40 \% & 60 \% & 80 \% & 100 \%
\end{array}
$$

- Strongly disagree $\square$ Disagree $\quad$ Neutral $\quad$ Agree $\square$ Strongly agree

Figure 9 The response of participants related to follow preventive measures even after vaccination.

If you are willing not to take the vaccine, then what you think is the most appropriate reason for your willingness

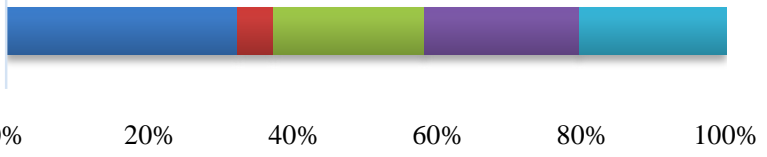

- Crowd at the vaccination center, which may cause COVID to you

- Charge of the vaccine

- Not able to find a vaccination center

- Not sure about the side effects of vaccine

- Other

Figure 10 The response of participants about possible reason for reluctancy of COVID-19 Vaccine uptake.

If in upcoming day government starts the vaccination for the age group below 18, will you get your children vaccinated? (Fill only if you are a parent)

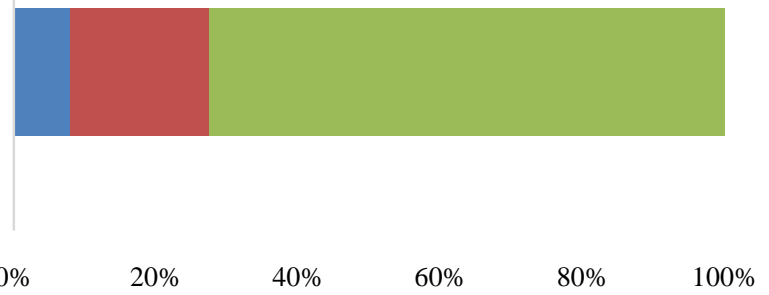

No $\quad$ Not sure $\quad$ Yes

Figure 11 The response of parents about the willingness to get their children vaccinated.

Even after vaccination, the majority of respondents (77.7\%) strongly support the idea of implementing all preventive measures, such as sanitization, wearing masks, and social distancing, as recommended by government health organizations (Figure 9).

In response to the question, if you are unwilling to take the vaccine, then what do you think is the most appropriate reason for your unwillingness. Most of the respondents showed their concern about getting infected at the vaccination center (32\%). A nearly equal proportion of participants $(21 \%)$ answered that they would be unable to locate a vaccination center and that they were unsure of the potential negative effects (Figure 10).
The concern regarding the availability of vaccines is significantly associated with age $(p<0.01)$, as the lower the age, the more concerns regarding the vaccine. Other factors like the authenticity of the vaccine, the rapid development of a vaccine, unforeseen future effects, a personal gain of pharmaceutical companies, and following preventive measures are significantly associated with residence $(\mathrm{p}<0.01)$ as more the backward area, lesser the knowledge regarding the vaccine. The authenticity of the vaccine was also associated with education ( $\mathrm{p}<0.05)$, as the more educated the person, the greater the queries regarding the vaccine. Factor like promoting personal gain of pharmaceutical companies is also associated with marital status $(\mathrm{p}<0.05)$ and socioeconomic status $(p<0.05)$ as more the socioeconomic status, more the concerns. 


\section{Discussion}

This web-based cross-sectional survey was done to investigate the paradigm shift in COVID-19 vaccination uptake and try to connect it to people's knowledge, opinions, and concern about COVID-19 immunization during the pandemic's second wave. The total number of participants who participated in this survey is 711 to complete the validated questionnaire based on their knowledge regarding the COVID-19 vaccine.

This study has found some similarities and dissimilarities regarding the willingness of vaccine uptake and consistent with the previous studies, the intent of vaccine uptake is associated with various socio-demographic aspects such as age, gender, place of residence, and education. (Kumari et al., 2021b)

There is a myriad of information sources that have a significant impact on vaccine knowledge. Even though the majority of the population $(80.9 \%)$ trusts credible sources of information, the information obtained through social media is a subject of concern. It was highlighted in previous studies that those who obtained their information from social media are less likely to get vaccinated (Wilson \& Wiysonge, 2020). This necessitates the communication of accurate vaccine information, particularly to persons who live in rural regions and have a lower socioeconomic standing. Results of the current study revealed that healthcare workers played quite a significant role in spreading factual information regarding the vaccine. This result is following a study in France which reveals that $72.4 \%$ of the participating health care are willing to get vaccinated, and $79.6 \%$ of them are eager to recommend it to their patients (Janssen et al., 2021).

Our result indicated that the majority of our participants are willing to accept the vaccine $(84.4 \%)$ which indicate that India has a higher vaccine acceptance than the U.S. (56.9\%) (Reiter et al., 2021) and France $(58.9 \%$ ) (Schwarzinger et al., 2021) but much lesser than countries like Indonesia (93.3\%) (Harapan et al., 2020) and China (91.3\%) (Wang et al., 2020).

The people of 45-65 years living in the urban area show more willingness to take vaccines even if they have to pay for them and are willing to recommend them to their family members.In line with the study conducted in China by Zhang et al. (2020), the parents in our study expressed a strong desire $(71.9 \%)$ to get their kids vaccinated as soon as it became accessible for children below age 18 (Figure 11).

Current knowledge and intention of vaccine uptake are generally higher than reported in the previous studies in India (Kumari et al., 2021b) as well as in Australia (Seale et al., 2021) and UK (Sherman et al., 2021). This is most likely due to a massive rise in corona cases during the second wave, which prompted people to learn more about the COVID-19 vaccine and change their habits. This might be the possible reason for the change in willingness about COVID-19 vaccine uptake.

The study revealed that the willingness to vaccine uptake increased however, the lack of knowledge regarding eligible candidates for the vaccine is a significant hurdle in the vaccination drive. People residing in rural areas having lesser education can be an essential factor for this. There is a high tendency towards acceptance of vaccine uptake in middle and high socioeconomic status populations.

Several facilitators that influence the vaccine uptake include the availability of vaccines at no cost, the opinion of their healthcare workers, the risk and benefits ratio of the vaccine, and its usefulness in eradicating the infection. A large number of participants felt that it is their social responsibility to get vaccinated. The zeal to eradicate this infection is the key driver of this mission and can be associated with vaccine acceptance. Though many factors influence vaccine acceptance, our study showed that there are a few concerns that may prevent people from getting vaccinated, such as vaccine availability and authenticity, serious side effects or unforeseen future effects, and pharmaceutical companies promoting commercial gain. Several additional research, similar to ours, have reported the same role of barriers and facilitators in vaccination campaigns (MacDonald et al., 2015; Graichen, 2021; Seong et al., 2021; Fisk, 2021; Saied et al., 2021).

\section{Conclusion}

This is a web-based cross-sectional survey that assessed the change in public intention towards vaccine acceptance during the prelaunching of vaccine to the second wave of COVID-19 periods. As the consequences of the second wave were terrifying, leading to high mortality. This changed the intent of participants about COVID-19 vaccine uptake. Several risks and trust factors are significant predictors of the intention of vaccine uptake. Vaccine apprehension is complicated and context-dependent, altering across time, place, and vaccine, as stated by the SAGE working group. It is critical to keep an eye on factors like complacency, convenience, and confidence as we are approaching the third wave. Aside from that, the Indian government is prioritizing vaccination based on several factors, including age, vaccination of healthcare workers, and immunization of frontline workers. Because other countries have either experienced or are experiencing the third wave, the Indian government should be prepared. It is critical to vaccinate an increasing number of people.

\section{Acknowledgments}

All the authors acknowledge and thank their respective Institutes and Universities. 


\section{Funding}

No substantial funding is to be stated.

\section{Disclosure statement}

All authors declare that there exist no commercial or financial relationships that could, in any way, lead to a potential conflict of interest.

\section{References}

Dubé E, Laberge C, Guay M, Bramadat P, Roy R, Bettinger J (2013) Vaccine hesitancy: An overview. Human Vaccines and Immunotherapeutics 9(8): 1763-1773. https://doi.org/10.4161/ hv. 24657

Fisk RJ (2021) Barriers to vaccination for coronavirus disease 2019 (COVID-19)control: experience from the United States. Global Health Journal 5(1): 51-55. https://doi.org/10.1016/ j.glohj.2021.02.005

Graichen H (2021) What is the difference between the first and the second/third wave of Covid-19? - German perspective. Journal of Orthopaedics 24: A1-A3. https://doi.org/10.1016/j.jor.2021.01.011.

Harapan H, Wagner AL, Yufika A, Winardi W, Anwar S, Gan AK, Setiawan AM, Rajamoorthy Y, Sofyan H, Mudatsir M (2020) Acceptance of a COVID-19 Vaccine in Southeast Asia: A CrossSectional Study in Indonesia. Frontiers in Public Health 8: 1-8. https://doi.org/10.3389/fpubh.2020.00381

India could see the third wave in 6-8 weeks if Covid-appropriate behavior is not followed: AIIMS chief Randeep Guleria (2021) Available at https://www.indiatoday.in/coronavirus-outbreak/story/ covid-19-third-wave-india-aiims-randeep-guleria-1816963-202106-19 accessed on 24.06.2021.

Janssen C, Maillard A, Bodelet C, Claudel A, Gaillat J, Delory T (2021) Hesitancy towards COVID-19 Vaccination among Healthcare Workers : A Multi-Centric Survey in France. Vaccines 9(6): 547.

Kumari A, Ranjan P, Chopra S, Kaur D, Upadhyay AD, Kaur T, Bhattacharyya A, Arora M, Gupta H, Thrinath A, Prakash B, Vikram NK (2021a) Development and validation of a questionnaire to assess knowledge, attitude, practices, and concerns regarding COVID-19 vaccination among the general population. Diabetes \& Metabolic Syndrome: Clinical Research \& Reviews 15(3): 919-925. https://doi.org/10.1016/j.dsx.2021.04.004

Kumari A, Ranjan P, Chopra S, Kaur D, Kaur T, Upadhyay AD, Isaac JA, Kasiraj R, Prakash B, Kumar P, Dwivedi SN, VikramNK (2021b) Knowledge, barriers and facilitators regarding COVID-19 vaccine and vaccination programme among the general population: A cross-sectional survey from one thousand two hundred and forty-nine participants. Diabetes and Metabolic Syndrome: Clinical Research and Reviews 15(3): 987-992. https://doi.org/10.1016/ j.dsx.2021.04.015

MacDonald NE, Eskola J, Liang X, Chaudhuri M, Dube E, Gellin B, Goldstein S, et al. (2015)Vaccine hesitancy: Definition, scope and determinants. Vaccine 33(34): 4161-4164. https://doi.org/ 10.1016/j.vaccine.2015.04.036

Ministry of home affairs, India (2021) Available at https://www.mygov.in/covid-19 accessed on 02.06.2021.

Office of the Registrar General \& Census Commissioner, India (2021) Available at https://censusindia.gov.in/ accessed on 15.05.2021.

Reiter PL, Pennell ML, Katz ML (2020) Acceptability of a COVID-19 vaccine among adultsin the United States: How many people would get vaccinated?. Vaccine 38(42): 6500-6507. https://doi.org/10.1016/j.vaccine.2020.08.043.

Saied SM, Saied EM, Kabbash IA, Abdo SAEF (2021) Vaccine hesitancy: Beliefs and barriers associated with COVID-19 vaccination among Egyptian medical students. Journal of Medical Virology 93(7): 4280-4291. https://doi.org/10.1002/jmv.26910.

Sallam M (2021) Covid-19 vaccine hesitancy worldwide: A concise systematic review of vaccine acceptance rates. Vaccines 9(2):1-15. https://doi.org/10.3390/vaccines9020160.

Schwarzinger M, Watson V, Arwidson P, Alla F, Luchini S (2021) COVID-19 vaccine hesitancy in a representative working-age population in France: a survey experiment based onvaccine characteristics.The Lancet Public Health 6(4): e210-e221. https://doi.org/10.1016/S2468-2667(21)00012-8.

Seale H, Heywood AE, Leask J, Sheel M, Durrheim DN, Bolsewicz K, Kaur R (2021) Examining Australian public perceptions and behaviors towards a future COVID-19 vaccine. BMC Infectious Diseases 21(1): 1-9. https://doi.org/10.1186/ s12879-021-05833-1.

Seong H, Hyun HJ, Yun JG, Noh JY, Cheong, HJ, Kim WJ, Song JY (2021) Comparison of the second and third waves of the COVID-19 pandemic in South Korea: Importance of early public health intervention. International Journal of Infectious Diseases 104: 742-745. https://doi.org/10.1016/j.ijid.2021.02.004.

Sherman SM, Smith LE, Sim J, Amlôt R, Cutts M, Dasch H, Rubin GJ, Sevdalis N (2021) COVID-19 vaccination intention in the UK: results from the COVID-19 vaccination acceptability 
study (CoVAccS), a nationally representative cross-sectional survey. Human Vaccines and Immunotherapeutics 17 (6): 16121621. https://doi.org/10.1080/21645515.2020.1846397.

Sulprizio M, Kleinert J, Belz J (2021) Mental health in Germany. Mental Health in Elite Sport. Routledge Taylor \& Francis group.

Vaccine Hesitancy: what it means and what we need to know in order to tackle it (2015) Available at https://www.who.int/ immunization/research/forums_and_initiatives/1_RButler_VH_Thr eat_Child_Health_gvirf16.pdf.

Wang J, Jing R, Lai X, Zhang H, Lyu Y, Knoll M D, Fang H (2020) Acceptance of covid-19 vaccination during the covid-19 pandemic in china. Vaccines 8(3): 482 https://doi.org/ 10.3390/vaccines8030482.

Wilson SL, Wiysonge (2020) Social media and vaccine hesitancy.
BMJ Global Health5(10): 1-7. https://doi.org/10.1136/bmjgh2020-004206.

World health organization, archived: WHO timeline- COVID-19 (2021) https://www.who.int/news/item/27-04-2020-who-timeline--covid-19 accessed on 17.06.2021.

World health organization, Coronavirus disease: Vaccine(2021) Available at https://www.who.int/news-room/q-a-detail/coronavirusdisease-(covid-19) vaccines? adgroupsurvey $=\{$ adgroupsurvey $\} \&$ gclid=Cj0KCQjw5auGBhDEARIsAFyNm9EW962QJ6FIgbOzn5X 1g9J-3_NEE_1cXucB0EAg1GI2V_O651QPJAoaAqKXEALw_wcB accessed on 17.06.2021

Zhang K, Fang Y, Cao H, Chen H, Hu T, Chen Y, Zhou X, Wang Z (2020) Parental Acceptability of COVID-19 Vaccination for Children Under the Age of 18 Years: Cross-Sectional Online Survey. JMIR Pediatr Parent3(2): e24827. doi: 10.2196/24827. 